\title{
Development of a new framework to identify pathways from socioeconomic development to
}

\author{
environmental pollution \\ Qi Wang ${ }^{1}$, Fangbai $\mathrm{Li}^{1 *}$ \\ 1, * Guangdong Key Laboratory of Integrated Agro-environmental Pollution Control and \\ Management, Guangdong Institute of Eco-environmental Science \& Technology, Guangzhou, \\ China
}

*Corresponding author: Fangbai Li (jenniferqi520@gmail.com)

\begin{abstract}
Socioeconomic development and environmental conservation are in perpetual conflict. Economic activities have affected the environment through a wide range of pathways (or processes). Understanding the pathways is paramount to accomplish the sustainability of society, environment and economy. However, the underlying causal pathways from socioeconomic development to environmental pollution remain obscure. In this study, we developed a framework to uncover causal pathways through which socioeconomic development affects environmental pollution. This framework was operationalized by linking macro- and microscale economic activities to heavy metal pollution through pollution pathways. The direct, indirect and hidden causal pathways and effects through which socioeconomic development caused soil $\mathrm{Cd}, \mathrm{As}, \mathrm{Pb}, \mathrm{Hg}$ and $\mathrm{Cr}$ pollution in the Pearl River Delta (PRD) of China from 2004 to 2014 were identified. Socioeconomic development caused the exacerbation of $\mathrm{Cd}$, $\mathrm{As}$, and $\mathrm{Pb}$ pollution mainly through agricultural and primary and secondary industrial activities and caused the reduction in $\mathrm{Hg}$ and $\mathrm{Cr}$ pollution primarily through secondary industrial activities. The contributions of industrial sources to $\mathrm{Cd}, \mathrm{As}, \mathrm{Pb}, \mathrm{Hg}$ and $\mathrm{Cr}$ pollution were $72.7 \%, 78.6 \%, 80.7 \%, 82.4 \%$ and $70.3 \%$, respectively. The difference in the impacts of socioeconomic development on heavy metal pollution hinges on the different effects of economic scale and structure and technology. $\mathrm{Hg}$ and $\mathrm{Cr}$ pollution was mainly caused by the strong effect of economic structure and technology, whereas the effect of the economic scale played a major role in $\mathrm{Cd}$, $\mathrm{As}$ and $\mathrm{Pb}$ pollution. Our study can provide insights
\end{abstract}


into socioeconomic development to ensure favorable environmental outcomes.

Keywords: Environmental pollution; socioeconomic development; causal pathway; economic activity; heavy metal. 